\title{
Protocolos de prevenção e enfrentamento da violência sexual no contexto universitário: uma análise do cenário latino-americano'
}

\section{Protocols for preventing and tackling sexual violence in the university context: an analysis of the Latin American scenario}

\author{
Yana Linhares ${ }^{\mathbf{a}}$ \\ (iD) https://orcid.org/0000-0003-1420-1906 \\ E-mail: yanaalinhares96@gmail.com \\ Jordana Fontanab \\ (i) https://orcid.org/0000-0001-8595-1590 \\ E-mail: jordanafontanaacœgmail.com

\section{Carolina Laurenti ${ }^{\mathrm{a}}$} \\ (iD) https://orcid.org/0000-0002-5247-9610 \\ E-mail: claurentiळuem.br
}

aUniversidade Estadual de Maringá. Centro de Ciências Humanas, Letras e Artes. Departamento de Psicologia. Maringá, PR, Brasil.

bUniversidade Estadual de Londrina. Centro de Ciências Biológicas. Departamento de Pós-Graduação em Análise do Comportamento. Londrina, PR, Brasil.

\section{Correspondência}

Carolina Laurenti

Universidade Estadual de Maringá. Centro de Ciências Humanas, Letras e Artes. Av. Colombo, 5.790, bloco I18, sala 4. Maringá, PR, Brasil. CEP 87020-900.

\section{Resumo}

A violência sexual é um problema de saúde pública presente em diversos contextos, inclusive nas universidades. 0 objetivo desta pesquisa documental foi sistematizar informações de 34 protocolos de prevenção e enfrentamento da violência sexual de universidades da América Latina. Foram analisados: ano de publicação; termos empregados para designar objetivos e diretrizes, bem como as referências utilizadas para conceituá-los; inclusão de marcadores sociais; âmbito de aplicação; e rede de apoio disponibilizada pela universidade. Do total, $75 \%$ dos protocolos foram criados entre 2015 e 2018, o que indica seu caráter recente. Quanto à terminologia, a noção de violência sexual permite uma descrição mais extensiva e objetiva de diferentes formas de violência, mostrando-se profícua na identificação do fenômeno. Quanto à abrangência da aplicação dos protocolos, é importante pautar a caracterização do contexto universitário pelos vínculos institucionais, e não apenas pelos limites espaciais dos campi, considerando tanto as relações presenciais quanto as virtuais. A rede de apoio disponibilizada pela universidade é um fator decisivo para o acolhimento e o encaminhamento mais efetivo dos casos. Conclui-se que, mesmo que a elaboração de protocolos seja uma política necessária para sancionar a responsabilidade da universidade, é preciso que ela seja integrada a ações suplementares, incluindo o desenvolvimento de novas pesquisas na área.

Palavras-chave: Violência Sexual; Universidade; Protocolos; Feminismos; Responsabilidade Social. 
Abstract

Sexual violence is a public health issue, and it is present in several contexts, including universities. This study systematized information found in 34 protocols for preventing and tackling sexual violence in Latin American universities. The following aspects were examined: year of publication; terms selected by protocols to designate goals and guidelines, as well as the references used to frame the concepts; social markers; the scope of application; and support network provided by universities. From the overall number, 75\% were created between 20152018, showcasing recent development. As for terminology, the notion of sexual violence allows for a wider and more objective account of diverse ways of violence, presenting a more fruitful manner of identifying the phenomenon. As for the scope of applicability of the policy, it is important to consider institutional ties, not only the spatial limits of campuses, as well as virtual relationships, and not just face-to-face. The support network provided by university stands as a decisive factor for more effective counseling and guidance of the occurrences. While the formulation of protocols remains a necessary policy to sanction the university's responsibility, it must be combined with complementary ones that include developing further research in this field.

Keywords: Sexual Violence; University; Policies; Feminisms; Social Responsibility.
A violência sexual é uma dentre as diferentes formas de violência vivenciadas pelas mulheres atualmente. De acordo com a Organização Mundial da Saúde, a violência sexual é entendida como um conjunto de atos sexuais, ou tentativa de obtê-los, que abarcam "comentários ou insinuações sexuais não desejadas, atos de tráfico ou dirigidos contra a sexualidade de uma pessoa usando coerção, por qualquer pessoa, independente de sua relação com a vítima, em qualquer contexto" (WHO, 2002, p. 149). No cenário mundial, a incidência da violência sexual é alarmante, e esse problema já tem sido reconhecido como uma questão de saúde pública (WHO, 2019). Estudos destacam que 35\% das mulheres do mundo já sofreram algum tipo de violência sexual durante sua vida (WHO, 2019).

Diversos autores e autoras têm indicado que a violência sexual também acontece no ambiente universitário (Fielding-Miller et al., 2019; Hill; Silva, 2005; McMahon et al., 2018), inclusive no Brasil (Almeida, 2019; Almeida, 2017; Bandeira, 2017; Costa, 2015; Cruz et al., 2018; Instituto Avon, 2015; Linhares; Laurenti, 2019; Maito et al., 2019a, 2019b), destacando, ainda, os múltiplos efeitos perniciosos dessa prática para a saúde física e mental de quem a vivencia (Hill; Silva, 2005; Linhares; Laurenti, 2019). Esse cenário torna ainda mais cogente a criação de políticas de enfrentamento e prevenção da violência sexual nesse contexto.

Além de iniciativas, nessa direção, tomadas por universidades da América do Norte (Vladutiu; Martin; Macy, 2010) e da Europa (Thomas, 2004), algumas universidades da América Latina também têm realizado ações que visam a prevenção, o enfrentamento e a erradicação da violência sexual. Muitas dessas ações vêm sendo condensadas e descritas em documentos denominados protocolos de assédio sexual.

Uma pesquisa denominada \#PasóEnLaU, realizada pela plataforma digital Distintas Latitudes e pela Red Latinoamericana de Jóvenes Periodistas em 2019, ${ }^{1}$ buscou investigar se universidades da América Latina dispunham ou não desses documentos. Esses protocolos especificam regras, estratégias e procedimentos que informam os passos a serem seguidos e quais os órgãos

1 As informações da pesquisa estão disponíveis em: <https://pasoenlau.distintaslatitudes.net/>. Acesso em: 17 mar. 2020. 
responsáveis por receber, processar, investigar e sancionar ou absorver denúncias de assédio ou abuso sexual no âmbito universitário.

Esses protocolos ou cartilhas são importantes ferramentas para dar visibilidade e auxiliar na identificação desse tipo de violência, tornando possíveis as denúncias, além de firmar a responsabilidade da universidade pelo enfrentamento dessas práticas. Dada a relevância dessas iniciativas, sobretudo no contexto latino-americano, em que essas ações ainda são incipientes, o objetivo deste estudo é sistematizar as principais informações contidas nesses protocolos. Com isso, espera-se constituir um panorama sobre algumas políticas de enfrentamento da violência sexual nas universidades da América Latina, o que pode conferir material útil a instituições que pretendem elaborar esse tipo de documento, ajudando-as a ponderar suas potencialidades e limites.

\section{Método}

Foi realizada uma pesquisa de natureza documental, cujas fontes foram protocolos de atenção, prevenção e sanção de casos de violência sexual, disponibilizados na página \#PasóEnLaU pela plataforma Distintas Latitudes e pela Red Latinoamericana de Jóvenes Periodistas. Esses documentos foram obtidos por meio da realização de uma pesquisa conduzida pela equipe desse projeto, constituída por jovens internacionalistas, cientistas políticos e jornalistas de todo continente. Essas autoras e autores entraram em contato com as universidades por meio de diversos canais institucionais, fazendo perguntas e solicitações de acesso a esses tipos de documento. Foram selecionadas 100 universidades públicas e privadas de 16 países da América Latina, conforme dois critérios: a quantidade de alunos matriculados e a qualidade do ensino das universidades - este último parâmetro aferido conforme o ranking da Quacquarelli Symonds, companhia britânica especialista em educação que publica o QS World University Rankings.

Das 100 universidades que participaram do estudo, 24 não responderam às solicitações de informações ou não tinham o protocolo disponibilizado publicamente, e somente 40 continham um protocolo de violência sexual; destes, apenas 36 eram protocolos de acesso público. No que diz respeito especificamente ao Brasil, a pesquisa entrou em contato com seis universidades: Universidade Norte do Paraná (Unopar), Universidade Paulista (Unip), Universidade de São Paulo (USP), Universidade Estadual de Campinas (Unicamp), Universidade Federal do Rio de Janeiro (UFRJ) e Pontifícia Universidade Católica do Rio de Janeiro (PUC-Rio). Quatro delas não responderam à pesquisa e das duas que responderam, somente uma (USP) possuía um protocolo de violência sexual. A pesquisa \#PasóEnLaU disponibilizou no seu site o link dos protocolos ${ }^{2}$ que tiveram acesso, sendo estes a fonte de análise deste artigo.

O conteúdo dos protocolos foi disposto na forma de tabelas, de modo a organizar os aspectos descritivos desses documentos conforme leitura de familiarização. As informações geradas a partir desse registro foram coligidas em eixos temáticos que permitiram dar relevo aos principais componentes estruturais desses protocolos.

\section{Resultados e discussão}

Foram analisados 34 protocolos reunidos pelo estudo do Distintas Latitudes e da Red Latinoamericana de Jóvenes Periodistas, visto que, dos 36 protocolos disponíveis, dois não apresentaram um link para acesso público. As informações registradas nas tabelas foram compiladas em termos de: (1) ano de publicação dos protocolos; (2) termos utilizados para designar as diretrizes e os objetivos do protocolo, bem como as referências bibliográficas para conceituá-los; (3) a inclusão de marcadores sociais; (4) abrangência de aplicação do protocolo; e (5) rede de apoio disponibilizada pela universidade para o acolhimento e/ou denúncias.

\section{A criação dos protocolos e o seu caráter recente}

A data de publicação dos protocolos pode ser conferida na Tabela 1.

2 Os protocolos utilizados neste artigo estão disponíveis em: <https://pasoenlau.distintaslatitudes.net/contexto/>. Acesso em: 17 mar. 2020. 


\section{Tabela I - Data de publicação dos protocolos das universidades selecionadas}

\section{Universidade}

Data de publicação

Universidad de Chile

Não apresenta

Universidad del Rosário

Não apresenta

Universidad Latinoamericana de Ciencia y Tecnología

Não apresenta

Universidad de Costa Rica

1997

Universidad Peruana Cayetano Heredia

2010

Universidad Centroamericana José Simeón Cañas

2011

Universidad de San Martin de Porres

201

Universidad Nacional Autónoma de Honduras

2012

Universidad de Buenos Aires

2015

Universidad Nacional de Córdoba

2015

Universidad Nacional de La Plata

2015

Universidad de los Andes

2016

Universidad Nacional Autónoma de México

2016

Instituto Politécnico Nacional

2016

Instituto Tecnológico Autónomo de México

2016

Pontificia Universidad Católica del Perú

2016

Universidade de São Paulo

2017

Pontificia Universidad Católica de Chile

2017

Universidad de Santiago

2017

Universidad Nacional de Colombia

2017

Universidad Nacional

2017

Universidad Central del Ecuador

2017

Tec de Monterrey

2017

Universidad Nacional de Rosario

2018

Universidade Andres Bello

2018

Pontificia Universidade Catolica de Valparaíso

2018

Pontificia Universidad Javeriana

2018 


\section{Universidade}

Instituto Tecnológico de Costa Rica

Escuela Superior Politecnica del Litoral

Pontificia Universidad Católica del Ecuador

Universidad de Guadalajara

Universidad Iberoamericana

Universidad Privada César Vallejo

Universidad Nacional Mayor de San Marcos

Total
Data de publicação

2018

2018

2018

2018

2018

2018

2018

34

Fonte: Distintas Latitudes e Red Latinoamericana de Jóvenes Periodistas ${ }^{3}$

Com exceção do protocolo da Universidad de Costa Rica, publicado em 1997, os demais protocolos foram publicados a partir de 2010, destacando-se um aumento progressivo no número de protocolos publicados ao longo dos anos. Dos 34 protocolos, $75 \%$ foram publicados entre 2015 e 2018 , e $32,35 \%$ deles se concretizaram em 2018, o que indica o caráter recente da formulação desse tipo de documento nas universidades da América Latina.

Algo que pode ter relação com o aumento da criação desses protocolos é a ascensão de novos campos de ação feminista (Alvarez, 2014) no continente sulamericano, com a pluralização de modos de constituir reivindicações e lutas. Um exemplo mais recente na Argentina foi o movimento \#NiUnaAMenos, que surgiu como forma de dar visibilidade aos casos de feminicídio e violência contra as mulheres. As mobilizações, de expressivas proporções, reuniram, em 2015, cerca de 400.00o pessoas em 240 locais da Argentina (Laudano, 2017). Em 2018, no Chile, também ocorreu um movimento em que as jovens chilenas ocuparam as instituições em defesa de uma universidade não-sexista e livre do assédio sexual. Uma reportagem realizada no ano das manifestações pelo jornal Brasil de Fato (Onda..., 2018) relatou como as políticas e a falta de protocolos nas universidades do país dificultavam a luta contra o machismo e a violência contra as mulheres nas instituições, o que resultou no movimento. Entre 2015, ano em que houve a manifestação \#NiUnaMenos na Argentina, e 2018 foi criada a maioria dos protocolos. Vale ressaltar ainda que três dos seis protocolos das universidades chilenas descritos na Tabela 1 foram criados no ano de 2018 , inclusive o da Universidad de Chile, a qual, segundo a reportagem, foi ocupada na época do movimento.

O protocolo da USP, ao qual a pesquisa \#PasóEnLaU teve acesso, foi criado em 2017. Bandeira (2017) cita uma variedade de casos de assédio sexual, estupro, trotes universitários degradantes e até mesmo a morte de um estudante na universidade. Essas práticas iam desde veteranos obrigando as(os) calouras(os) a simularem sexo entre eles, como aconteceu em 2014, passando pela ocorrência de casos de estupro em 2015, até a venda de um manual com teor degradante e discriminatório aos calouros em 2016. Em 2015, após a insatisfação da comunidade acadêmica com as medidas tomadas pela universidade contra casos de violência sexual, foi formada uma Comissão Parlamentar de Inquérito (CPI) que buscou investigar casos de violência na universidade. 0 relatório da CPI causou grande comoção e revolta pela quantidade de evidências, testemunhos e vídeos mostrando violência 
física, sexual e psicológica em diferentes instâncias da universidade. Nesse período, foi criada na USP a Rede Não Cala, com o objetivo de oferecer aconselhamento e apoio às vítimas de violência sexual, desenvolver ações educativas e contribuir para a elaboração e implementação de protocolos de investigação na universidade (Cruz et al., 2018). A data de criação do protocolo da USP levanta a possibilidade de que essa medida tenha sido realizada em resposta a todas essas mobilizações no campus.

Em suma, ao relacionar a data de confecção dos protocolos com o status dos movimentos de mulheres e feministas associados a eventos parlamentares que buscavam enfrentar a violência nos países da América Latina e no cenário mundial, pode-se conjecturar uma possível conexão entre o crescimento dessas políticas com o dos movimentos sociais, o que sugere uma interface profícua entre esses movimentos, sobretudo os feministas, e a academia na luta contra a violência sexual nas universidades.

\section{Sobre terminologias e definições}

Outro aspecto investigado foram os termos utilizados pelos protocolos para reportar qual tipo de violência estavam abordando (e.g., assédio sexual, violência sexual, violência de gênero) e as fontes bibliográficas que poderiam pautar a definição desses termos. Para isso, foram analisados os títulos dos protocolos que indicavam a natureza da violência a qual o protocolo se referia (e.g., política preventiva contra o assédio sexual; cartilha sobre violência de gênero na universidade; ações contra atos de violência sexual), e identificadas e descritas, quando possível, as referências bibliográficas mencionadas para conceituar os termos dispostos no documento.

De acordo com os dados, 41,17\% dos protocolos utilizaram somente o termo "assédio sexual"; $20,58 \%$, a expressão "violência de gênero"; 2,94\%, apenas "violência sexual"; $2,94 \%$, somente "violência"; um deles (2,94\%) não foi encontrado; e os outros $29,41 \%$ utilizam mais de um termo, alguns incluindo também conceitos como "discriminação", "ameaça”, dentre outros.

Esses conceitos foram definidos de formas similares pelos protocolos analisados. Por exemplo, o termo "assédio sexual", mais recorrente entre os protocolos, foi definido pela Universidad Peruana Cayetano Heredia (2010, p. 2) com base nas leis do país, como:

conduta física ou verbal repetida de natureza sexual ou outros comportamentos de conotação sexual não desejada e/ou rejeitada por uma ou mais pessoas que se aproveitam de uma posição de autoridade ou hierarquia ou qualquer outra situação vantajosa, contra outra ou outras, que rejeitem essas condutas por considerar que afetam sua dignidade assim como seus direitos fundamentais.

Por seu turno, a Universidad Nacional (2017, p. 1), de Costa Rica, apesar de não ter descrito a fonte bibliográfica, conceituou assédio sexual como: “a imposição não desejada de requerimentos ou favores sexuais em uma relação desigual de poder, que influencie negativamente as possibilidades, o desempenho, condições ou ambiente de trabalho ou educacional daqueles que o sofrem".

As definições têm em comum o fato de as condutas sexuais envolvidas no ato não serem desejadas pela pessoa que as sofre; tais ações podem ter expressões físico-corporais e verbais; e o ato violento se dá em uma relação hierárquica, na qual condutas sexuais não desejadas são perpetradas por alguém que está em uma posição superior na hierarquia acadêmica em relação a outrem. 0 assédio sexual, por exemplo, pode ser praticado por professores que se valem de sua posição hierarquicamente superior para intimidar, desqualificar e ameaçar alunas. Essa situação dificulta a denúncia por parte delas, que podem deixar de realizar uma queixa formal como forma de evitar as possíveis consequências negativas daí decorrentes, não só para vida pessoal, mas também para a acadêmica (Linhares; Laurenti, 2019).

A diversidade de formas com as quais o assédio sexual pode acontecer, envolvendo não só violência física, mas também psicológica e verbal (e.g., comentários com teor sexual, como piadas, e ameaças verbais com intenção de receber favores sexuais) (Pamplona Filho, 2002), destaca a importância de os protocolos abarcarem essas distintas expressões da violência, muitas das quais são veladas e inconspícuas e, por vezes, consideradas socialmente aceitas. Porém, outros atos sexualmente violentos, além do assédio 
sexual, podem ocorrer no âmbito de relações que não estão perpassadas por distinções academicamente hierárquicas, como relações entre os próprios professores, ou relações entre alunas(os).

Um aspecto que tem sido destacado no escopo dessa discussão é a prevalência de agressões sexuais perpetradas por pessoas conhecidas, como colegas de faculdade (DeKeseredy; Hall-Sanchez; Nolan, 2017; O'Connor et al., 2018). Por exemplo, uma pesquisa realizada por Fielding-Miller et al. (2019), em uma universidade da África do Sul, mostrou que 93\% dos agressores eram conhecidos das vítimas, tendo como principais contextos as festas universitárias. No Brasil, esse fenômeno acontece principalmente nos trotes. Nessas situações, há a imposição de hierarquias tradicionais e antigas de gênero e raça, ou seja, há uma reprodução das desigualdades presentes na sociedade por meio dessas práticas ritualizadas (Almeida, 2017). Esses rituais indicam a que grupo os estudantes irão pertencer, com uma separação por gerações entre o grupo "mais forte" (veteranos) e o "mais fraco" (calouros) (Akerman et al., 2012; Almeida, 2017). Assim, mesmo que a relação entre alunos(as) não seja caracterizada por uma distinção hierárquica formal, como a que se verifica entre professor-aluno, pode haver, a exemplo dos trotes universitários, uma hierarquia entre acadêmicos. Esse ponto precisa ser ponderado quando da aplicação do termo "assédio", pois se abarcar somente a distinção hierárquica formal da estrutura universitária, pode não ser abrangente o suficiente para incluir todos os vínculos presentes no contexto da instituição, no domínio dos quais a violência sexual pode acontecer.

As concepções de "violência de gênero" descritas pelos protocolos de algumas universidades também se assemelharam. A Pontificia Universidad Católica del Ecuador (2018) utilizou a definição da Organização Mundial da Saúde (OMS) de 2013 para definir a violência de gênero como:

todo ato de violência que resulte, ou possa ter como resultado um dano físico, sexual ou psicológico para a mulher, incluindo as ameaças a tais atos, a coação ou a privação arbitrária de liberdade, tanto se se produzem na vida pública ou na privada. (OMS, 2013 apud Pontificia Universidad Católica del Ecuador, 2018, p. 9)
A Universidad Iberoamericana (2018, p. 29), do México, por sua vez, conceituou violência de gênero com base na Suprema Corte de Justiça da Nação, definindo-a como "qualquer violência exercida contra uma pessoa em função da sua identidade ou expressão de gênero, sem distinção de sexo, tanto no âmbito público quanto privado".

Não obstante a sua relevância para dar visibilidade a formas de violência contingentes ao gênero, amiúde negligenciadas, o termo "violência de gênero", sem detalhamento suplementar, pode dificultar, pelo seu caráter genérico, a identificação de ações envolvidas nesse tipo de violência. Em vista disso, parece ser necessário utilizar termos e definições que permitam identificar e descrever concretamente quais comportamentos são passíveis de denúncia. Segundo Maito et al. (2019b), a falta de uma definição formal e detalhada dificulta o reconhecimento da situação como violenta, impactando, por conseguinte, no enfrentamento efetivo por parte da universidade.

O uso do termo "violência sexual", verificado em alguns protocolos, parece ser uma alternativa viável para evitar esses problemas. A Universidad Nacional de Colombia (2017, p. 11) utilizou-se de diversas referências para conceituar violência sexual como uma violência exercida para

impor à pessoa vitimizada que desenvolve ou tolera uma determinada ação sexual ou que mantém contato sexualizado, físico ou verbal, contra sua vontade, através do uso da força, coerção, pressão psicológica, ameaça, intimidação, suborno, chantagem, manipulação ou qualquer outro mecanismo que anule ou limite a vontade pessoal.

A USP (2017, p. 9) pautou-se na definição jurídica de violência sexual, conforme o Código Penal Brasileiro de 1940, mas também a complementou com uma conceituação própria, caracterizando-a como "forçar a prática de atos que causam desconforto ou repulsa como, por exemplo, sexo forçado; impedir o uso de método contraceptivo; forçar uma gravidez; forçar um aborto; toques e carícias não desejados".

Para o contexto nacional, em particular, a utilização do termo "violência sexual" pode se mostrar útil, especialmente tendo em vista a sua definição pelo Código Penal Brasileiro de 1940. 
O código estipula que "violência sexual" abrange diversos crimes contra a liberdade e dignidade sexual, como a importunação sexual (e.g., atos de cunho sexual praticados contra alguém, de modo não consensual, com o objetivo de satisfazer a própria lascívia ou a de terceiros), o assédio sexual (e.g., constranger alguém a realizar atos sexuais aproveitando-se de sua posição hierárquica superior), a violação sexual mediante fraude (e.g., atos sexuais após a vítima ingerir substâncias sem estar ciente), e o estupro (e.g., ato sexual sem consentimento). Assim, por ser um termo abrangente, mas que permite a descrição de ações específicas, pode contribuir para a identificação de atos de violência sexual nas universidades, mostrando-se, portanto, como um termo potencialmente profícuo para o uso em protocolos no país.

No entanto, vale ponderar, como argumenta Almeida (2019), que a definição de violência sexual varia de acordo com os valores vigentes em determinada sociedade, principalmente aqueles ditados pelo grupo dominante, o que se configura como uma "batalha semântica". A compreensão do que é definido como violência sexual pode ser dificultada devido ao julgamento moral das vítimas: mulheres tendem a ser culpadas caso estivessem presentes em festas universitárias, consumindo bebidas alcoólicas ou usando roupas curtas, por exemplo. Outro fator que dificulta a classificação de um ato como violência sexual é a existência de um estereótipo de agressores sexuais como indivíduos monstruosos, tornando difícil conceber um "bom aluno" como agressor, o que pode levar à impunidade dos agressores (Almeida, 2019).

Além disso, essa "batalha semântica" põe em pauta o que se considera por consentimento, conceito-chave para que um ato se classifique como violência sexual (Almeida, 2019). Um exemplo deste tipo de situação foi um caso de estupro coletivo que ocorreu em uma universidade da Espanha, em 2016. Nesse episódio, a sentença imputada aos agressores de nove anos de prisão foi pautada no entendimento dos juízes de que o ato foi um abuso sexual e não uma agressão sexual (estupro), devido à aparente passividade da jovem. Somente em 2019, após diversas manifestações no país, esta pena foi corrigida com uma mudança no projeto de lei que incluiu a necessidade de consentimento explícito para um ato sexual
(Contra..., 2020). Esses fatores destacam a necessidade de a elaboração de protocolos ser orientada por uma discussão contextualizada histórica e culturalmente da violência sexual, considerando os valores sociais e as dificuldades que perpassam a conceptualização do termo.

No que diz respeito às referências utilizadas para a definição dos conceitos, 52,94\% das universidades utilizaram da legislação nacional, como o Código Penal ou a Constituição do respectivo país, e 23,52\% de outras fontes, como os relatórios da OMS, declarações universais, artigos científicos, dentre outras. Por um lado, as descrições jurídicas e legislativas são importantes principalmente para tipificar os casos e para amparar e reivindicar legalmente políticas de enfrentamento da violência sexual conforme as especificidades de cada país. Por outro lado, por se utilizar de nomenclatura técnica, é possível que a linguagem seja inacessível e de difícil compreensão para a comunidade acadêmica como um todo.

Algumas universidades dedicaram uma parte dos seus protocolos para discutir e contextualizar a violência de gênero de maneira geral, seja com uso de artigos, declarações universais, e documentos de instituições. Um exemplo é a Pontificia Universidad Católica del Ecuador (2018), que utilizou não só de definições da OMS, mas também de artigos científicos para discorrer sobre como a violência contra as mulheres é fruto da desigualdade entre os gêneros e de um conjunto de normas sociais e culturais que regulam comportamentos dos homens e das mulheres, sendo um dos tipos de violação de direitos humanos mais presentes no mundo. Outro exemplo é o protocolo da Universidad Nacional de Rosario (2018, p. 3) que, embora não tenha referenciado as fontes em seu texto, pontuou que "as violências sexistas são parte de uma estrutura sustentada desde um sistema patriarcal, que continua persistindo na nossa sociedade e reproduzindo práticas e relações de poder opressivas, violentas e discriminatórias".

Crocker (1983) elenca uma série de razões que justificam a importância da elaboração de definições, bem como a contextualização sociocultural de práticas sexualmente violentas, que ocorrem no âmbito universitário: promover debates; educar a comunidade acadêmica acerca de comportamentos e experiências que são reconhecidas como passíveis 
de punição; possibilitar a notificação de professores que estão praticando o assédio sexual; e servir como orientação para a postura de administradores perante as reivindicações de alunas(os).

Essas análises sugerem que é necessário apresentar definições abrangentes e, ao mesmo tempo, objetivas de violência sexual de modo a contribuir para a descrição dos comportamentos passíveis de denúncia. Adicionalmente, destaca-se a importância de dar relevo ao caráter sociocultural dessas formas de violência, colocando em xeque concepções essencialistas do fenômeno e a naturalização de comportamentos sexualmente violentos, impelindo, outrossim, a universidade a se posicionar em termos de seu papel social na luta contra práticas sexistas e violentas na sociedade.

\section{A inclusão de marcadores sociais}

Outro aspecto que ganhou destaque nas análises foi se os protocolos incluíam ou não marcadores sociais da diferença como raça, etnia, gênero, orientação sexual, entre outros, na conceituação da violência sexual. Essa inclusão é relevante na medida em que a frequência de ocorrência da violência sexual, a forma como ela é perpetrada e os seus efeitos perniciosos podem se dar de maneira diferencial em função desses parâmetros sociais, requerendo, portanto, uma abordagem interseccional (Maito et al., 2019a).

Segundo Maito et al. (2019a), a universidade, como instituição social, reproduz discriminações sociais presentes na sociedade influenciadas pela ideologia dominante. Grupos subalternizados como pessoas negras, indígenas e em situação de pobreza, bem como as mulheres, sofrem um processo de opressão estrutural que, ao longo da história, os têm excluído da universidade e do processo da produção de conhecimento. Maito et al. (2019a) citam estudos realizados na USP que evidenciaram situações de violência diária perpassadas por questões de gênero, raça, classe social, características pessoais, dentre outras, identificadas, por exemplo, no âmbito de relações entre veterano-calouro e professor-aluno. Com isso, as autoras destacam a necessidade de uma perspectiva mais interseccional, articulando a violência sexual e de gênero com outras formas de opressão.
Dos protocolos analisados, 79,41\% incluíram o gênero, 44,11\% consideraram também a orientação sexual e 29,41\% incluíram a raça ou etnia. Um exemplo é a Pontificia Universidad Javeriana (2018, p. 7), a qual, além de definir uma alta gama de conceitos como violência, violência sexual, assédio, violência de gênero, violência intrafamiliar e entre outros, considerou como discriminação

atos nos quais uma pessoa arbitrariamente impede, obstrui ou restringe o pleno exercício dos direitos de outras pessoas por razão de sua raça, etnia, nacionalidade, idade, sexo ou orientação sexual, incapacidade, condição econômica, religião, ideologia política ou filosófica, entre outros.

Essa discussão mostra-se importante porque, segundo Bandeira (2017, p. 77),

o machismo, o racismo, a lesbofobia, a bifobia e outras formas discriminatórias interagem diretamente entre si produzindo e reproduzindo relações de violências e de poder que ditam qual é o papel da jovem universitária [e da mulher] na sociedade patriarcal e capitalista, assim como do jovem do sexo masculino estão ainda longe de serem erradicados.

Uma compreensão interseccional dá visibilidade ao caráter multidimensional da violência sexual, chamando a atenção para uma plêiade de aspectos e interseções que conferem especificidades ao fenômeno e que não podem ser negligenciadas em sua análise, sob pena de se incorrer em outras práticas violentas e em revitimização.

\section{Âmbito de aplicação do protocolo}

Foi também averiguado o que estava sendo considerado pelos protocolos como contexto ou ambiente universitário, o que ajuda a elucidar a compreensão da universidade do que poderia ser considerado um caso de violência sexual sob sua jurisdição. Para explicitar esse ponto, foi observada a caracterização dos protocolos de contexto universitário em termos: dos indivíduos que o compõem e das funções que desempenham na universidade; dos limites espaciais (prédios, estabelecimentos) e 
não-espaciais (vínculos institucionais); e do tipo de relação (presencial ou virtual) no escopo da qual poderia acontecer a violência sexual.

No que se refere aos sujeitos envolvidos, 97, o6\% dos protocolos consideraram que a violência sexual universitária pode abranger toda a comunidade acadêmica, que pode ser definida como "grupo de pessoas integrado por alunos, professores, os funcionários e diretores de todos ou de cada um dos campus do Tecnológico Monterrey” (Tecnológico Monterrey, 2017, p. 8).

Sobre a demarcação dos limites do ambiente universitário que os protocolos abrangem, apenas $26,47 \%$ reputaram atos de violência sexual praticados no âmbito universitário como aqueles que acontecerem nas dependências físicas da universidade. De maneira mais abrangente, $61,76 \%$ entenderam que violência sexual universitária pode ocorrer em outros espaços físicos que não nas dependências do campus, mas que estejam, de alguma forma, vinculados à universidade, como, por exemplo, locais de estágio. Pode-se citar como exemplo a USP (2017, p. 24), ao estabelecer que a denúncia poderá ser realizada "se a violência acontecer nas dependências da Universidade (no campus, em festas oficiais e não oficiais, trabalhos de campo, atividades extracurriculares etc.)".

Além disso, 32,35\% dos protocolos abarcaram não somente as instalações vinculadas à universidade, mas também os diferentes tipos de relações dos indivíduos com a instituição. Isso foi pontuado, por exemplo, pela Universidad Central del Ecuador (2017, p. 8), ao descrever que os protocolos devem ser aplicados "nos campos principais, extensões ou modalidades presenciais, semipresenciais ou a distância e ações de vinculação com a sociedade e todo espaço de inter-relação entre os membros da comunidade universitária”.

Embora $64,70 \%$ dos protocolos tenham circunscrito as ações de violência sexual a relações presenciais, $23,52 \%$ também consideraram que os casos de violência sexual podem acontecer em meios virtuais. Um exemplo é Universidad Nacional de Colombia (2017, p. 11), cujo protocolo especificou que a penalidade descrita "também se aplica quando a conduta é realizada em espaços virtuais ou fora da Universidade, sempre que a pessoa vitimada pertença ao corpo discente, professor ou administrativo".

Um exemplo corrente de violência sexual que acontece nos meios virtuais é o slut shaming. De acordo com Sousa (2017), nesses casos são expostos na internet vídeos ou fotos de uma mulher, com conteúdo sexual sem consentimento, bem como ocorre a exposição e a humilhação nas mídias sociais em decorrência de suas práticas sexuais. Ainda segundo a autora, esse tipo de violência pode acarretar diversos danos psicológicos para quem é exposto, especialmente porque muitas vezes há a culpabilização pelo fato, levando a um processo de revitimização.

Um documento elaborado pela Comissão para Apurar Violência contra Mulheres e Gêneros do Campus USP de Ribeirão Preto (CAV-Mulheres) destacou a importância de se entender que a responsabilidade da universidade não deve se restringir ao ambiente físico do campus, mas ao que se denomina de "ambiente universitário” (Maito et at., 2019b). Este termo especifica que as relações universitárias acontecem não apenas nas dependências físicas, mas também no âmbito virtual; o termo "ambiente universitário" abarca também locais em que integrantes da universidade estejam reunidos em nome da instituição - como palestras, seminários, viagens -, e relações entre indivíduos que ocorrem em função da universidade, inclusive fora da USP, como festas com associações universitárias, por exemplo. Esse entendimento de "ambiente universitário" permite abranger casos de violência sexual que ocorrem em trotes universitários, cujas atividades podem se dar fora das dependências da universidade, mas que estão relacionadas a ela por ser um "rito de passagem" para a iniciação da graduação, podendo, como já indicado, constituir-se em mais um meio de transmissão de práticas culturais violentas no ambiente acadêmico (Almeida, 2017).

\section{A rede de apoio proporcionada pela instituição}

A rede de apoio acionada pela universidade para lidar com casos de violência sexual também foi alvo de análise. Constatou-se que 50\% das universidades possuem órgãos constituídos exclusivamente para lidar com as queixas relacionadas a esse tipo de violência, como comissões, equipes interdisciplinares, núcleos de atendimentos a mulheres em situação de 
violência sexual, entre outros. 0 restante delas orienta que os casos sejam direcionados para órgãos que já fazem parte do campus e que não são destinados exclusivamente para os casos de violência sexual, como a reitoria, a secretaria geral do campus ou o tribunal universitário.

Uma das universidades que apresentou órgãos internos específicos para lidar com situações de violência sexual foi a Pontificia Universidad Catolica de Valparaíso (2018). Nessa instituição, há uma comissão para prevenção, acompanhamento e sanção de condutas de assédio, violência e discriminação, a qual é constituída por indivíduos que pertencem a diferentes posições na estrutura acadêmica (discentes, docentes, técnicos/as) e com variadas expertises (campo jurídico, psicológico, assistência social etc.), permitindo que haja diferentes olhares e perspectivas para lidar com a situação. A Pontificia Universidad Católica de Chile (2017), por exemplo, recorre a órgãos já existentes na universidade para a realização da denúncia, sendo eles representados pelas autoridades da unidade à qual a vítima pertence e a Secretaria Geral do campus.

Analisando pela rede de apoio das universidades, $58,82 \%$ dos protocolos descreviam o encaminhamento dos casos reportando-se apenas a órgãos restritos às dependências da universidade, 38,23\% também contavam com órgãos externos para lidar com os casos, como delegacia, Ministério Público, e Ministério do Trabalho, por exemplo, e um protocolo citou apenas órgãos externos para lidar com os casos. Esses dados sugerem que grande parte das universidades lida com os casos no âmbito de suas dependências, evitando o envolvimento de instâncias públicas exteriores ao seu contexto e a comunidade externa, o que pode estar relacionado ao sigilo. Adicionalmente, isso pode sugerir a tomada de responsabilidade das instituições quanto aos encaminhamentos necessários.

Mesmo que a universidade não disponha de órgãos específicos para lidar com os casos, e os encaminhe para órgãos já existentes, é possível desenvolver outras estratégias. Um exemplo é dado pela Universidade Nacional Autónoma do México, a qual criou procedimentos específicos no âmbito dos órgãos universitários já existentes para o enfrentamento da violência sexual e de gênero, realizando capacitação dos trabalhadores da vigilância universitária em assuntos como violência de gênero, direitos humanos, segurança e legislação universitária, o que pode ensejar um encaminhamento mais justo desses casos.

A efetividade desse processo é essencial para a resolução dos casos, sendo necessário que a universidade conte com profissionais que sejam capacitados/as para lidar com a violência sexual sem levar a um processo de revitimização e esquecimento. De acordo com Almeida (2017), nos últimos anos, as instituições estão se mobilizando para lidar com as situações de violência sexual na universidade por meio de comissões internas de sindicância, de serviços relacionados à igualdade de gênero e da mobilização de órgãos externos.

Porém, segundo Costa (2015), a celeridade do processo é comprometida em função da burocratização nos encaminhamentos dos casos de violência sexual, visto que as sindicâncias acabam ocorrendo em sigilo e, não raro, ultrapassam os prazos estipulados para sua resolução, o que aumenta a chance de os casos não terem um desfecho, ou uma resolução em tempo hábil. Além disso, a criação, a implementação e o aprimoramento de estratégias de combate à violência sexual podem encontrar outros obstáculos no interior das próprias universidades, a exemplo da iniciativa Rede Não Cala da USP, organizada por professoras e pesquisadoras para auxiliar alunas(os) que passaram por situação de violência sexual universitária. Segundo Almeida (2019), apesar de essa iniciativa ser um importante avanço, o grupo que a promoveu é pequeno se comparado com o volume do corpo docente da USP. De acordo com a autora, vê-se, ainda, uma falta de disposição política em criar centros de acolhimento, processos de investigação mais eficazes e programas de educação e elucidação sobre o tema. Almeida (2019) afirma que isso ficou evidente quando foram analisados os serviços de assistência social, e como a equipe precisava ser treinada e ampliada para resultar em um trabalho mais efetivo. A falta de efetividade no encaminhamento das denúncias da universidade dificulta o suporte às vítimas em direção ao registro da queixa, visto que podem ser revitimizadas, culpabilizadas ou humilhadas no processo.

O documentário The hunting ground (2015), dirigido por Kirby Dick, mostra que essa realidade faz parte também das universidades americanas. No documentário, a ex-reitora, assistente dos 
estudantes da Universidade da Carolina do Norte de Chapel Hill, relata ter recebido pelo menos 100 denúncias de agressões sexuais, sendo que, em nenhum desses casos, os agressores foram removidos do campus. Segundo o documentário, devido à constante impunidade dos agressores, $88 \%$ das mulheres sexualmente agredidas nos campi das universidades dos Estados Unidos não prestam queixa, apenas $26 \%$ dos casos relatados à polícia levam à prisão e $\mathbf{2 0} \%$ a um processo jurídico.

\section{Considerações finais}

As políticas contra a violência sexual nas universidades têm crescido nos últimos anos na América Latina, o que demonstra um avanço importante por parte dessas instituições; a produção de protocolos é uma das expressões dessas iniciativas. Contudo, protocolos e elaboração de políticas institucionais formais não garantem necessariamente o tratamento adequado do problema; isso porque, como afirma Almeida (2019), "existe um abismo entre a lei e sua aplicação”. Segundo Maito et al. (2019a, p. 3), "a criação de normas é insuficiente, visto ser necessário que os problemas sejam efetivamente enfrentados pelas instituições legalmente responsáveis".

É preciso considerar, outrossim, que muitas vezes essas estratégias podem funcionar como forma de silenciamento, o que pode ser evidenciado nas universidades americanas. Segundo Dauber e Warner (2019), os Estados Unidos vêm sofrendo um retrocesso nas políticas de combate à agressão sexual desde a posse do presidente Donald Trump que, dentre outros efeitos, alterou políticas institucionais que dificultaram as denúncias de violência sexual e a responsabilização das universidades. O documentário The hunting ground (2015) também ilustra como as universidades americanas, mesmo aquelas com discursos e políticas de enfrentamento à violência sexual, tentavam constantemente silenciar as(os) estudantes para que não "manchassem" o nome da universidade.

No que diz respeito especificamente ao Brasil, fica conspícua a necessidade de se investir em mais políticas contra a violência sexual nas universidades, uma vez que das seis universidades brasileiras contatadas pelo estudo \#PasóEnLaU, somente uma (USP) dispunha, à época, de um protocolo. No entanto, é necessário salientar que, não obstante a importância desses documentos, é preciso que essas políticas sejam associadas a outras, como a constituição de comissões, elaboração de diretrizes e códigos de conduta, formação e educação de pessoal para capacitar e lidar com violações contra direitos humanos. Um exemplo nessa direção é a Rede Não Cala da USP, cujas estratégias concentraram-se em: (1) dar acolhimento às vítimas de violência, com iniciativas como fornecer uma lista de professores para escuta e possibilidades de encaminhamento; (2) proporcionar ações educativas como conversas, palestras, cartilhas; e (3) auxiliar no aprimoramento de mecanismos de protocolos investigativos (Cruz et al., 2018).

Mesmo com o investimento em protocolos e políticas institucionais formais, restam alguns desafios em relação ao cenário brasileiro. Nas universidades brasileiras há, de maneira geral, uma estrutura hierárquica e os cargos mais altos são ocupados por homens, o que prejudica não só o encaminhamento efetivo dos casos, mas também as concepções do que poderia ser considerado passível de denúncia, pois relativiza a violência nos casos em que os perpetradores não atendem aos estereótipos de um agressor (Almeida, 2019).

Cruz et al. (2018) pontuam ainda que as universidades reproduzem valores culturais presentes na sociedade. No caso do Brasil, há uma cultura sexista, misógina, homofóbica, racista e com altos índices de desigualdade social e econômica, o que demonstra que as universidades tendem a ser um espaço com altos índices de desigualdade, dando ensejo a ações violentas contra grupos considerados minoritários. Além disso, há um agravante contemporâneo: um governo conservador que tem apresentado um retrocesso às conquistas relacionadas aos direitos humanos e à luta feminista (Arruzza; Bhattacharya; Fraser, 2019), o que dificulta a implementação de políticas públicas voltadas ao enfrentamento da violência. Considerando todos esses aspectos, é necessário atentar-se aos mecanismos de silenciamento e reprodução de desigualdade e violência de gênero nas universidades, promovendo mudanças por meio de medidas de investigação mais efetivas, práticas de 
ensino, mudanças na cultura da instituição, apoio às vítimas e responsabilização dos agressores (Cruz et al., 2018; Maito et al., 2019a).

Destaca-se a importância de se realizar mais trabalhos acadêmicos sobre o assunto, de modo que políticas sejam elaboradas com base em estudos e pesquisas, garantindo mecanismos de prevenção e denúncia mais eficientes. Este estudo subscreve essa tese procurando agregar informações e reflexões a outras pesquisas que já têm sido realizadas no país sobre a violência sexual no contexto universitário (Almeida, 2019; Almeida, 2017; Bandeira, 2017; Costa, 2015; Cruz et al., 2018; Linhares; Laurenti, 2019; Maito et al., 2019a). Por outro lado, destaca-se também as limitações deste estudo que podem dar ensejo a outras investigações sobre essa temática. 0 número de protocolos alcançados foi reduzido, tendo em vista a quantidade de universidades da América Latina. É necessário ponderar, ainda, que os protocolos podem ter se modificado desde a pesquisa de \#PasóEnLaU e outros podem ter sido criados em período ulterior (e.g., Maito et al., 2019b). Além disso, pode haver mais universidades com protocolos com as quais esta pesquisa não entrou em contato. De qualquer modo, a criação de políticas de enfrentamento e prevenção, associadas às pesquisas acadêmicas e ao constante diálogo com movimentos sociais, são articulações que precisam ser construídas e fortalecidas para que a universidade não seja mais um contexto favorável à manutenção e perpetuação de práticas sexualmente violentas na sociedade.

\section{Referências}

AKERMAN, M. et al. Revelando fatos, sentidos, afetos e providências sobre o trote em uma faculdade de medicina: narrativa de uma experiência. Revista Brasileira de Educação Médica, Rio de Janeiro, v. 36, n. 2, p. 249-254, 2012.

ALMEIDA, H. B. Violence sexuelle et de genre à l'université: du secret à la bataille pour la reconnaissance. Brésil(s): Sciences Humaines et Sociales, Paris, n. 16, 2019. Não paginado.

ALMEIDA, T. M. C. Violências contra mulheres nos espaços universitários. In: STEVENS, C. et al. (Org.). Mulheres e violências: interseccionalidades. Brasília, DF: Technopolitik, 2017. p. 384-399.

ALVAREZ, S. E. Para além da sociedade civil: reflexões sobre o campo feminista. Cadernos Pagu, Campinas, v. 43, p. 13-56, 2014.

ARRUZZA, C.; BHATTACHARYA, T.; FRASER, N. Feminismo para os 99\%: um manifesto. São Paulo: Boitempo, 2019.

BANDEIRA, L. M. Trotes, assédios e violência sexual nos campi universitários no Brasil. Revista Gênero, Niterói, v. 17, n. 2, p. 49-79, 2017.

CONTRA abuso, governo da Espanha apresenta projeto que exige consentimento explícito para ato sexual. G1, São Paulo, 3 abr. 2020. Disponível em: <https://glo.bo/383 ${ }_{3} \mathrm{BG}$. Acesso em: 23 jul. 2020.

COSTA, M. B. (Re)pensando o abuso sexual em contexto universitário: afeto, compartilhamento e a construção de fatos. 2015. Trabalho de conclusão de curso (Bacharelado em Ciências Sociais) Universidade de Brasília, Brasília, DF, 2015.

CROCKER, P. L. An analysis of university definitions of sexual harassment. Journal of Women in Culture and Society, New York, v. 8, n. 4, p. 696-707, 1983.

CRUZ, E. F. et al. Don't stay silent: network of female professors against gender violence at University of São Paulo. Annual Review of Critical Psychology, [s. l.], v. 15, p. 223-245, 2018.

DAUBER, M. L.; WARNER, M. O. Legal and political responses to campus sexual assault. Annual Review of Law and Science, Palo Alto, v. 15, p. 311-333, 2019.

DEKESEREDY, W. S.; HALL-SANCHEZ, A.; NOLAN, J. College campus sexual assault: the contribution of peers' proabuse informational support and attachments to abusive peers. Violence Against Women, Thousand Oaks, v. 24, p. 922-935, 2017.

FIELDING-MILLER, R. et al. Epidemiology of campus sexual assault among university women in Eswatini. Journal of Interpersonal Violence, Thousand Oaks, p. 1-26, nov. 2019.

HILL, C.; SILVA, E. Drawing the line: sexual harassment on campus. Washington, DC: 
American Association of University Women Education Foundation, 2005.

INSTITUTO AVON. Violência contra a mulher no ambiente universitário. São Paulo, 2015. Disponível em: <https://bit.ly/38oxJmE>. Acesso em: 17 mar. 2020.

LAUDANO, C. N. Movilizaciones \#niunamenos $\mathrm{y} \#$ \#ivasnosqueremos en Argentina: entre el activismo digital y \#elfeminismolohizo. In: SEMINÁRIO INTERNACIONAL FAZENDO GÊNERO, 13., Florianópolis, 2017. Anais... Florianópolis: UFSC, 2017.

LINHARES, Y.; LAURENTI, C. Uma análise de relatos verbais de alunas sobre situações de assédio sexual no contexto universitário. Perspectivas em Análise do Comportamento, São Paulo, v. 9, n. 2, p. 234-247, 2019.

MAITO, D. C. et al. A universidade como reflexo e agente transformador da sociedade: a contradição movendo a história. Interface: Comunicação, Saúde, Educação, Botucatu, v. 23, e190711, 2019a.

MAITO, D. C. et al. Construção de diretrizes para orientar ações institucionais em casos de violência de gênero na universidade. Interface: Comunicação, Saúde, Educação, Botucatu, v. 23, e180653, 2019b.

MCMAHON, S. et al. Campus sexual assault: future directions for research. Sexual Abuse, Thousand Oaks, v. 31, n. 3, p. 270-295, 2018.

O'CONNOR, J. et al. Students' articulation of subtle rape myths surrounding campus sexual assault. Journal of College Student Development, Baltimore, v. 59, n. 4, p. 439-455, 2018.

ONDA feminista no Chile: por que as mulheres estão ocupando as universidades? Brasil de Fato, São Paulo, 18 maio 2018. Disponível em: <https:// bit.ly/3rc7hOz>. Acesso em: 17 mar. 2020.

PAMPLONA FILHO, R. Assédio sexual: questões conceituais. In: GOMES, L. F.; JESUS, D. E. (Org.). Assédio sexual. São Paulo: Saraiva, 2002. p. 109-135. PONTIFICIA UNIVERSIDAD CATÓLICA DE CHILE. Acciones ante hechos de violencia sexual. Santiago, 2017. Disponível em: <https://bit.ly/2PztB71>. Acesso em: 17 mar. 2020.
PONTIFICIA UNIVERSIDAD CATÓLICA DE VALPARAÍSO. Reglamento para la prevención, investigación y sanción de actos de acoso, hostigamiento, violencia y discriminación arbitraria. Valparaíso, 2018. Disponível em: <https://bit.ly/389UPaG>. Acesso em: 17 mar. 2020. PONTIFICIA UNIVERSIDAD CATÓLICA DEL ECUADOR. Protocolo de actuación frente a casos de violencia de género. Quito, 2018. Disponível em: <https://bit.ly/2O2nXcX>. Acesso em: 20 mar. 2020. PONTIFICIA UNIVERSIDAD JAVERIANA. Protocolo para la prevención, atención, acompañamiento, orientación y seguimiento de casos de violencias $y$ discriminación em la Pontificia Universidad Javeriana. Bogotá, DC, 2018. Disponível em: <https://bit.ly/3rbtjB7>. Acesso em: 20 mar. 2020.

SOUSA, L. M. Slut shaming e porn revenge: vivências de mulheres jovens e as repercussões para a saúde mental. 2017. Dissertação (Mestrado em Psicologia Social) - Universidade Federal da Paraíba, João Pessoa, 2017.

\section{TECNOLÓGICO DE MONTERREY. Protocolo} de actuación para la prevención y atención de violencia de género em el Instituto Tecnológico y de Estudios Superiores de Monterrey. Monterrey, 2017. Disponível em: <https://bit.ly/3uN2LZ4>. Acesso em: 21 mar. 2020.

THE HUNTING ground. Direção de Kirby Dick. Produção de Amy Ziering. Los Angeles: Chain Camera Pictures, 2015. Vídeo on-line (103min).

THOMAS, A. M. Politics, policies and practice: assessing the impact of sexual harassment policies in UK universities. British Journal of Sociology of Education, Abingdon, v. 25, n. 2, p. 143-16o, 2004.

UNIVERSIDAD CENTRAL DEL ECUADOR. Protocolo general para la prevención, atención y sanción de los casos de violencia sexual y de género. Quito, 2017. Disponível em: <https://bit.ly/3qgQ6ub>. Acesso em: 20 mar. 2020.

UNIVERSIDAD IBEROAMERICANA. Protocolo para la prevención y atención de violencia de género en la Universidad Iberoamericana. Tijuana, 2018. Disponível em: <https://bit.ly/zellBkv>. Acesso em: 20 mar. 2020. 
UNIVERSIDAD NACIONAL. Reglamento para prevenir, investigar y sancionar el hostigamiento sexual en la Universidad Nacional. Heredia, 2017. Disponível em: <https://bit.ly/3egeawv>. Acesso em: 20 mar. 2020.

UNIVERSIDAD NACIONAL DE COLOMBIA. Protocolo para la prevención y atención de casos de violencias basadas en género y violencias sexuales en la Universidad Nacional de Colombia. Bogotá, DC, 2017. Disponivel em: 〈https://bit.ly/3riqVIG〉. Acesso em: 20 mar. 2020.

UNIVERSIDAD NACIONAL DE ROSARIO.

Protocolo de acción institucional para

la prevención e intervención ante situaciones de violencia y discriminación de género. Rosario, 2018. Disponível em: <https://bit.ly/3uTwQGx>.

Acesso em: 20 mar. 2020.

UNIVERSIDAD PERUANA CAYETANO HEREDIA. Procedimiento preventivo y sancionador, de la UPCH, para la interposición de quejas en casos de hostigamiento sexual (docentes). San Martín de Porres, 2010. Disponível em: <https://bit. ly/2O4CQLQ>. Acesso em: 20 mar. 2020.

USP - UNIVERSIDADADE DE SÃO PAULO.

Violência de gênero na universidade: onde buscar ajuda? Conheça seus direitos. São Paulo, 2017. Disponível em: <https://bit.ly/3kJOpnG>. Acesso em: 20 mar. 2020.

VLADUTIU, C. J.; MARTIN, S. L.; MACY, R. J. College- or university-based sexual assault prevention programs: a review of program outcomes, characteristics, and recommendations. Trauma, Violence, \& Abuse, Thousand Oaks, v. 12, n. 2, p. 67-86, 2010.

WHO - WORLD HEALTH ORGANIZATION. Sexual violence: world report on violence and health.

Geneve, 2002.

WHO - WORLD HEALTH ORGANIZATION. Violence against women: intimate partner and sexual violence against women. Geneve, 2019. Disponível em: <https://bit.ly/302xwLu>. Acesso em: 17 mar. 2020.

\section{Contribuição das autoras}

Todas as autoras conceberam o projeto, delinearam o método a ser empregado e redigiram o artigo. Linhares e Fontana analisaram e interpretaram os dados. Laurenti realizou a revisão crítica do texto e aprovou a versão a ser publicada.

Recebido: 31/07/2020

Aprovado: 09/09/2020 